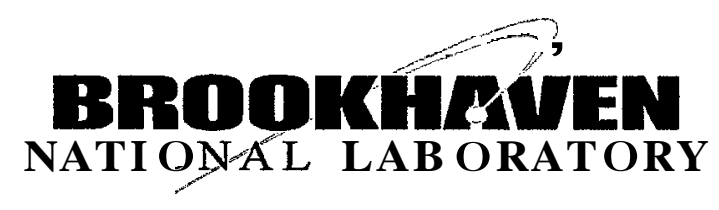

BNL-73495-2005-CP

\title{
Development o NEG Coating For RHIC Experimental Beamtubes
}

\author{
D. Weiss, P. He, H.C. Hseuh, R. Todd \\ Presented at the Particle Accelerator Conference(PAC'05) \\ Knoxville, Tennessee \\ May 16-20,2005
}

Collider-Accelerator Department

Brookhaven National Laboratory

P.O. Box 5000

Upton, NY 11973-5000

www.bnl.gov

Managed by

Brookhaven Science Associates, LLC

for the United States Department of Energy under

Contract No. DE-AC02-98CH10886

This is a preprint of a paper intended for publication in a journal or proceedings. Since changes may be made before publication, this preprint is made availablewith the understanding that it will not be cited or reproducedwithout the permission of the author. 


\section{DISCLAIMER}

This report was prepared as an account of work sponsored by an agency of the United States Government. Neither the United States Government nor any agency thereof, nor any of their employees, nor any of their contractors, subcontractors, or their employees, makes any warranty, express or implied, or assumes any legal liability or responsibility for the accuracy, completeness, or any third party's use or the results of such use of any information, apparatus, product, or process disclosed, or represents that its use would not infringe privately owned rights. Reference herein to any specific commercial product, process, or service by trade name, trademark, manufacturer, or otherwise, does not necessarily constitute or imply its endorsement, recommendation, or favoring by the United States Government or any agency thereof or its contractors or subcontractors. The views and opinions of authors expressed herein do not necessarily state or reflect those of the United States Government or any agency thereof.

FOR UNCLASSIFIED, UNLIMITED STI PRODUCTS

Available electronically at:

OSTI:

\section{http://www.osti.gov/bridge}

Available for a processing fee to U.S. Department of Energy and its contractors, in paper from:

U.S. Department of Energy

Office of Scientific and Technical Information

P.O. Box 62

Oak Ridge, TN 37831

Phone: (865) 576-8401

Facsimile: (865) 576-5728

E-mail: reports@adonis.osti.gov

National Technical Information Service (NTIS):

Available for sale to the public from:

US. Department of Commerce

National Technical Information Service

5285 Port Royal Road

Springfield, VA 22131

Phone: (800) 553-6847

Facsimile: (703) 605-6900

Online ordering: http://www.ntis.gov/ondering.htm 


\title{
DEVELOPMENT OF NEG COATING FOR RHIC EXPERIMENTAL BEAMTUBES*
}

\author{
D. Weiss", P. He, H.C. Hseuh, R. Todd, BNL, Upton, NY, 11973 U.S.A.
}

\section{Abstract}

As RHIC beam intensity increases beyond original scope, pressure rises have been observed in some regions. The luminosity limiting pressure rises are associated with electron multi-pacting, electron stimulated desorption and beam induced desorption. Non-Evaporable Getter (NEG) coated beamtubes have been proven effective to suppress pressure rise in synchrotron radiation facilities. Standard beamtubes have been NEG coated by a vendor and added to many RHIC UHV regions. BNL is developing a cylindrical magnetron sputtering system to NEG coat special beryllium beamtubes installed in RHIC experimental regions, It features a hollow, liquid cooled cathode producing power density of $500 \mathrm{~W} / \mathrm{m}$ and deposition rate of 5000 Angstrom $/ \mathrm{hr}$ on $7.5 \mathrm{~cm}$ OD beamtube. The cathode, a titanium tube partially covered with zirconium and vanadium ribbons, is oriented for horizontal coating of $4 \mathrm{~m}$ long chambers. Ribbons and magnets are arranged to provide uniform sputtering distribution and deposited NEG composition. Vacuum performance of NEG coated tubes was measured. Coating was analyzed with energy dispersion spectroscopy, auger electron spectroscopy and scanning electron microscopy. System design, development, and analysis results are presented.

\section{INTRODUCTION}

RHIC has a circumference of $3.8 \mathrm{~km}$ and comprises two interweaving rings for counter rotating beams. The two rings intersect at six locations. Superconducting magnets operating at $4.2 \mathrm{~K}$ occupy $>80 \%$ of each ring. The remaining beamline is warm straight sections of $-1.5 \mathrm{~km}$, including 24 standard and 18 common regions.

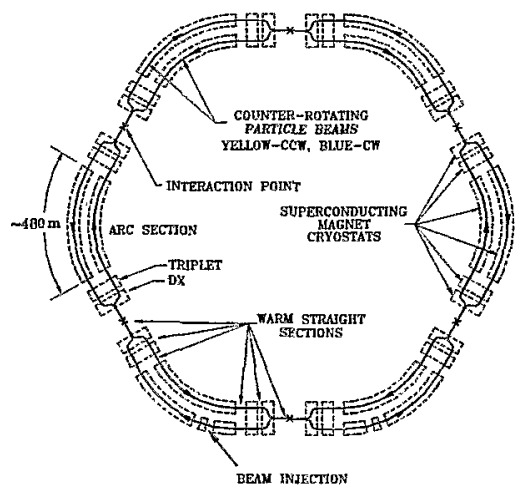

Figure 1: RHIC Ring Schematic

\footnotetext{
*Work performed under Contract No. DE-AC02-98CH10886 under the auspices of the U.S. Department of Energy. \#dweiss@bnl.gov
}

Each standard warm section is $34 \mathrm{~m}$ long. The 18 common regions include 6 interaction regions (IR), and 12 final focusing regions to steer the beams to collisions in the $\mathbb{R}$. The design vacuum of the warm sections is $<5 \times 10^{-10}$ torr [1][2]. Warm section beamlines bracketing each IR are shown in Figure 2. Warm sections are pumped by ion pumps and titanium sublimation pumps. The pumping speed at the pump inlet is $-500 \mathrm{l} / \mathrm{s}$ for active gases such as $\mathrm{CO}$ and $\mathrm{H}_{2}$. Due to the small linear conductance of the beam tubes, effective pumping speeds are in the order of tens $1 / \mathrm{s} \cdot \mathrm{m}$ for $\mathrm{H}_{2}$ and a few $1 / \mathrm{s} \cdot \mathrm{m}$ for CO. With few exceptions the warm sections are in-situ bakeable up to $250^{\circ} \mathrm{C}$. Average pressures of the warm sections without beam are below the design vacuum level.

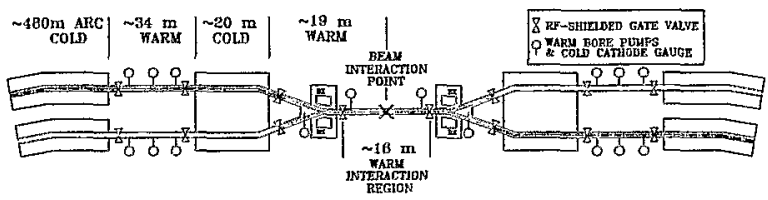

Figure 2: Typical RHIC Blue and Yellow Beam lines, highlighting warm \& cold bore vacuum regions symmetricalabout each $\mathbb{R}$.

Pressure rises of several decades have been observed in warm sections as intensity rose above the original RHIC specification in the last few years. Beam induced pressure rises have lead to high detector background rates and was a major luminosity-limiting factor for RHIC [3]. Modest improvement in the intensity threshold was realized following numerous bakeouts. As RHIC intensity goals continue to climb measures to suppress pressure rises are sought. Improvement of the vacuum systems during subsequent shutdowns included NEG coated beamtubes installed at the warm straight sections.[3]

\section{NON-EVAPORABLE GETTER PIPES}

\section{NEG Considerationsfor RHIC}

To increase the effective pumping speed and combat beam induced pressure rises, linearly distributed pumps in the form of a NEG coating are specified [3]. Distributed pumping is more effective than additional discrete pumps where little transverse space is available for large ion pumps and the longitudinal conductance is small. NEG coatings provide effective pumping speed of $10^{2} 1 / \mathrm{s} \cdot \mathrm{m}$ and also reduce the secondary electron yields, and the electron and ion desorptionrates [4].

\section{NEG Coating of Standard Beam Tubes}

Originally developed by CERN, a low activation temperature NEG coating process is applied routinely to chambers by SAES and ESRF [4]. Over 250 meters of 
stainless steel beam tubes in $5 \mathrm{~m}$ long sections has been coated by SAES and installed in RHIC. SAES applies the NEG film one microns thick on a vertical coating setup, via magnetron sputtering process using twisted wires of zirconium, vanadium and titanium as the cathode. The NEG film can be activated at a modest temperature of $\sim 200 \mathrm{C}$. Figure 3 illustrates the low activation temperature range of compositions [5]. Activation at 200C is conveniently integrated into the RHIC in-situ bakeouts.

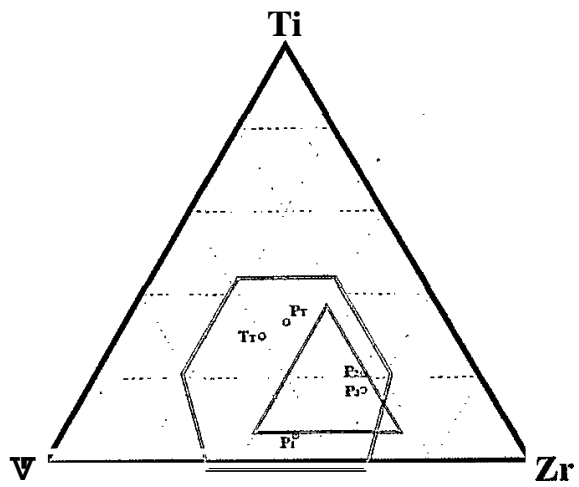

Figure 3. Acceptable Coating Composition Range (Red) and BNL sputter sample results indicated within.

\section{NEG Coating of Experimental Beam Tubes}

Standard $12 \mathrm{~cm}$ diameter 304L stainless steel beam tubes are very robust. Constructed mainly of thin-wall beryllium with various brazed transitions, the $7 \mathrm{~cm}$ diameter RHIC experimentalbeam tubes are quite fragile. The replacement cost and lead time, coupled with existing BNL sputtering capability led BNL to develop in-house NEG coating capability.

\section{Magnetron Sputtering Facility}

A magnetron sputter coating facility developed at BNL for TiN coating SNS chambers was adapted NEG film application. Chambers are oriented exclusively in the horizontal position throughout the process as shown in Figure 4.

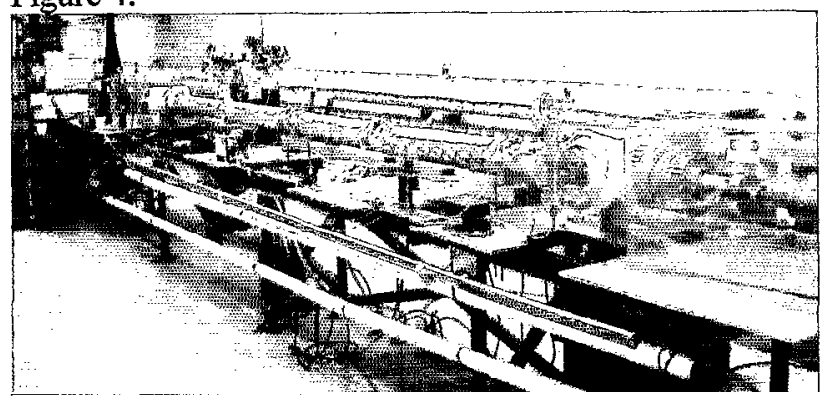

Figure 4. Magnetron sputtering set-up for NEG coating of $4.0 \mathrm{~m}$ long $\mathrm{x} 7.6 \mathrm{~cm}$ ID RHIC experimental beryllium beam tubes. Shown is the stainless steel test beamtube with distributed viewports.

Similar to the TiN coating facility, the NEG coating facility utilizes a coaxial hollow liquid-cooled cathode. Permanent magnet strings are contained within the hollow cathode to enhance ionization as shown schematically in Figure 5.

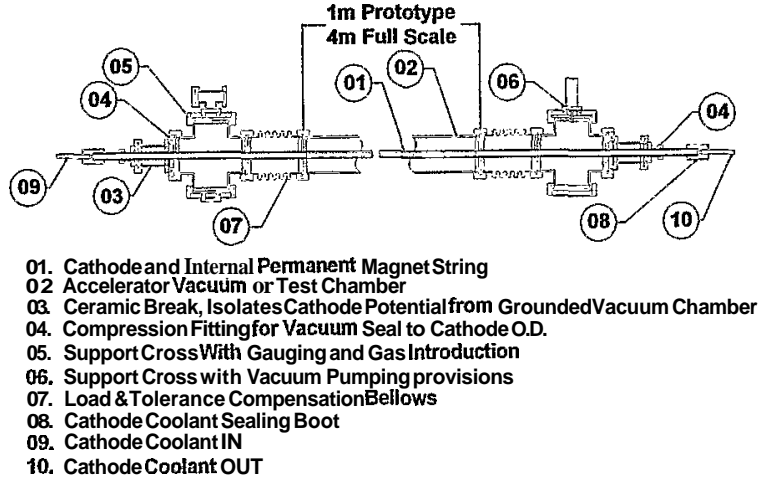

Figure 5. NEG sputter coating facility schematic

\section{NEG Cathode Design}

The cathode is composed of a titanium tube partially covered with $0.5 \mathrm{~m}$ long and $0.5 \mathrm{~mm}$ thick ribbons of zirconium and vanadium. Each ribbon is roll-formed into a helix. The ribbon widths and helix pitch angle are specified to establish the desired sputtering composition based on the sputter yields provided in Figure 6 for the expected sputtering voltage. A section of the 4 meter long NEG cathode is pictured in Figure 7.

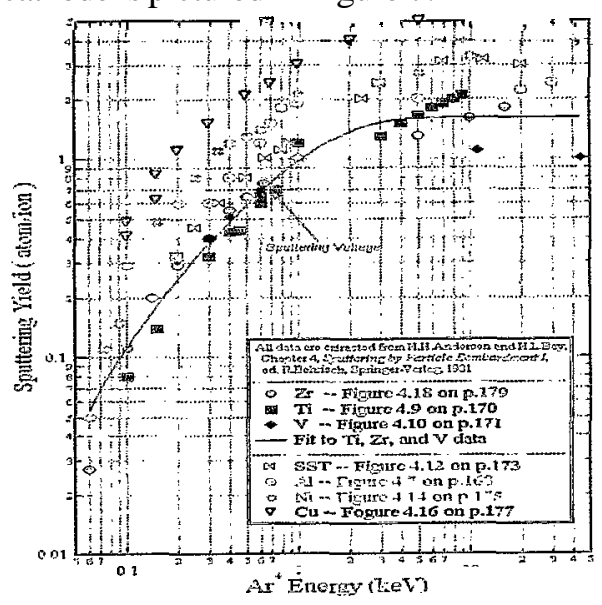

Figure 6. Sputter yields for NEG elements [6]

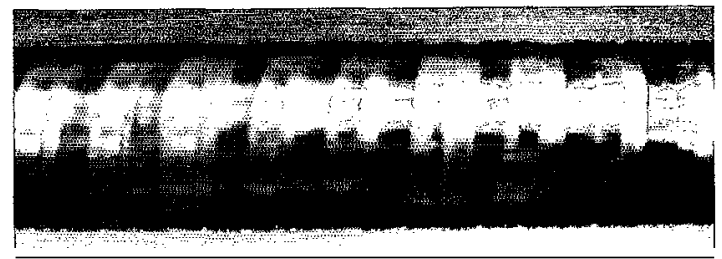

Figure 7. Section of the $4 \mathrm{~m}$ long NEG Cathode

Ribbons and magnets are arranged to provide uniform sputtering distribution and deposited NEG composition. The sputtering uniformity is estimated using a cosine distribution assuming each magnet in the string is a point source. Spacers between magnets of a string used for coating large diameter chambers are eliminated to improve the longitudinal uniformity on the smaller diameter experimental beam tubes. Predicted coating uniformity is shown in Figure 8. 


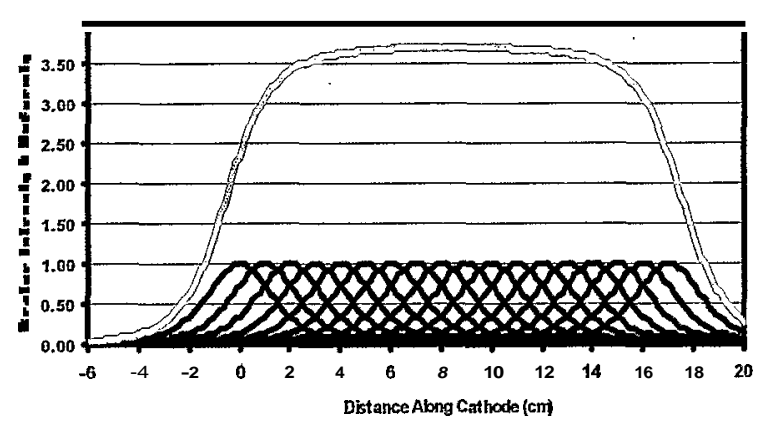

Figure 8. Cosine coating distribution. Magnets modeled as individual sources. Total distribution, shown in red, achieved by superposition of several magnet sources.

Establishing and sustaining the discharge along the full length in the $7.6 \mathrm{~cm}$ diameter beam tube is achievable with this latest cathode design and is verified by viewing through the distributed viewports as seen in Figure 9.

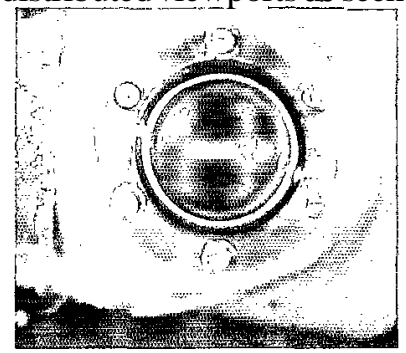

Figure 9. Typical discharge observed at all viewports of test beam tube using the 1" diameter supported cathode.

A high current of $-1 \mathrm{OA}$ is required to initiate a Uniform discharge along the entire $4 \mathrm{~m}$ length. The current is subsequently reduced to a few amps for the duration of the coating process. In the absence of viewports for actual beam tube coating, thermocouples distributed along the surface of the beam tube for bakeout monitoring serve indicators of a local temperature rise when the discharge is establishednearby.

\section{NEG Coating Results}

Vacuum performance of NEG coated sample tubes was measured using a test set-up shown in Figure 10.

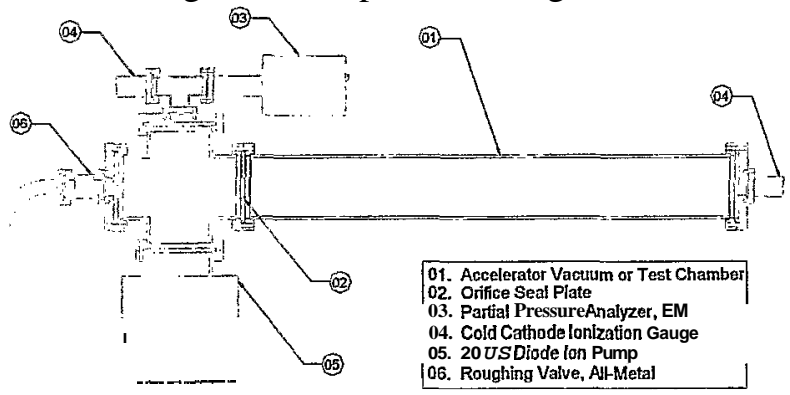

Figure 10. Schematic to evaluate the vacuum performance of NEG coated beam tubes. An orifice separates the coated tube and control volume allowing comparison of changes in NEG film and ion pump pumping speeds.

Pressure on both sides of the orifice was monitored and recorded throughout the process. The entire test system is evacuated and subjected to the standard RHIC in-situ bakeout and activation process. Following bakeout, the NEG coated tube temperature is elevated to $200 \mathrm{C}$ to activate the NEG film.Naturally, a reduction in pressure on both sides of the orifice is observed following bakeout, but solid evidence of NEG activation is observed via the pressure inversion across the orifice following activation as observed in Figure 11.

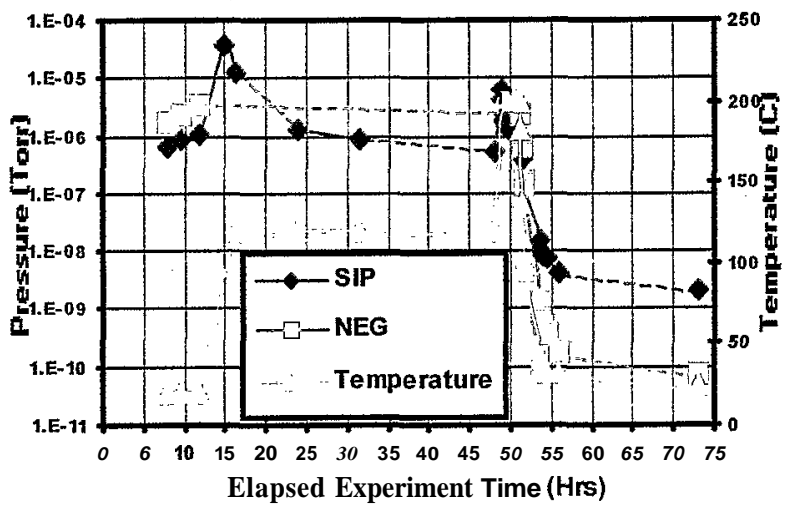

Figure 11. Typical Pressure vs temperature profile for NEG sample tube and control volume, showing pressure inversion following NEG activation.

Energy dispersive spectroscopy scans reveal coating composition is within the targeted range. Sample results in Figure 12 give a Ti-Z-V wt\% composition of 17-57-26.

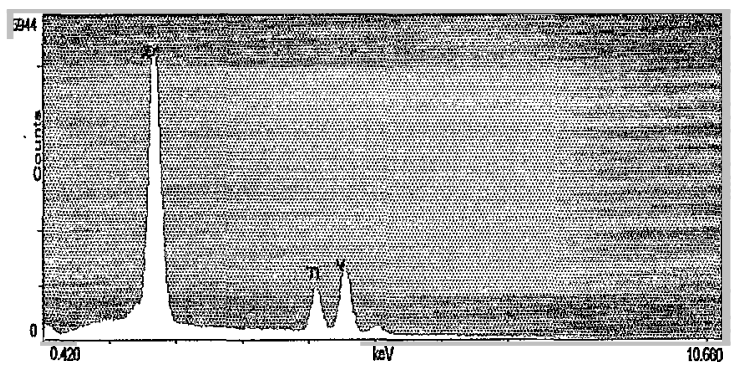

Figure 12.EDS results for NEG coated coupon

\section{SUMMARY}

Existing BNL sputtering technology, has been adapted to apply NEG film to RHIC experimental beamtubes. Reduced risk is realized with the ability to apply NEG films in-house. Improvement of the RHIC beam vacuum and increases in RHIC luminosity are expected [3].

\section{REFERENCES}

[1] M.J. Rhoades-Brown and M. A. Harrison, RHIC Technical Note\#106, BNL-47070, Dec. 1993.

[2] H.C. Hseuh, et al, Proc. PAC'99, 557 (1999).

[3] H.C. Hseuh, et al, 'Upgrade of RHIC Vacuum for High Luminosity Operation', these proceedings.

[4] C. Benvenuti, Proc. PAC01, Chicago, 602 (2001)

[5] C. Benvenuti et. al. Vacuum, 60 (2001), p57.

[6] H.H. Anderson, H.L. Bay, Sputtering by Ion Bombardment, Chapter 4,1981 